\title{
Transmural myocardial infarction in young women taking oral contraceptives Evidence of reduced regional coronary flow in spite of normal coronary arteries
}

\author{
HEINZ-JÜRGEN ENGEL, HEINZ HUNDESHAGEN, AND PAUL LICHTLEN \\ From the Division of Cardiology, Department of Medicine and the Division of Nuclear Medicine, \\ Department of Radiology, Medical University Hannover, West Germany
}

A normal coronary arteriogram after transmural myocardial infarction is a well-recognised phenomenon, but the pathophysiology remains unclear in most cases. A possible aetiological role of oral contraceptives is suggested by the occurrence of unequivocal myocardial infarction with normal or near normal coronary arteries in 4 young women who had been taking oral contraceptives. While the cause-effect relation of coronary thrombosis and myocardial infarction remains controversial in patients with coronary atherosclerosis, a primary occlusion of macroscopically normal coronary arteries by cellular elements of blood appears possible in these cases. The action of contraceptives, then, would be analogous to their thrombogenic effect in peripheral veins and cerebral arteries.

Absence of atherosclerotic lesions in these patients favours spontaneous thrombolysis and restoration of normal vessel patency in many of these cases. Myocardial blood flow in the region of the damaged lefi ventricular wall remains low in spite of normal coronary arteries. Reduced perfusion in infarcted areas is assumed to be the consequence of structural and functional alterations at precapillary and capillary level rather than an effect of obstructive coronary disease.

Myocardial infarction in patients with normal coronary arteries is reported with increasing frequency. Though this syndrome is still poorly understood, it seems today from clinical, angiographic, and postmortem evidence that myocardial infarction in young women taking oral contraceptives may represent a specific subgroup of this disease. The following presentation of 4 additional cases will attempt to analyse the pathophysiology of this subgroup and discuss the pathogenic role of contraceptives in myocardial infarction. Special emphasis will be put on regional myocardial blood flow in the area of infarction supplied by angiographically normal coronary arteries because so little is known about this subject (Lichtlen et al., 1976). Moreover, the study of regional myocardial blood flow in these patients might lead to some conclusions with regard to the pathophysiology of this specific syndrome and of coronary heart disease in general.

Received for publication 3 September 1976

\section{Methods}

Coronary and left ventricular angiocardiography were performed by the Sones or Judkins techniques. In each case the angiograms were carefully analysed for coronary lesions using multiple LAO and RAOprojections. Left ventriculograms were performed in 45 degree RAO-projections.

In 3 of the 4 patients, regional myocardial perfusion was analysed both by (1) the Xenon residue detection technique (Ross et al., 1964; Dwyer et al., 1973; Hundeshagen et al., 1976); and (2) by microsphere perfusion scintigraphy (Ashburn et al., 1971).

\section{XENON RESIDUE DETECTION}

The praecordial Xenon clearance technique was performed by use of a Pho-Gamma-3 Nuclear Chicago scintillation camera in conjunction with a CDC 1700 computer. After intracoronary injection of $10 \mathrm{mCi}^{133} \mathrm{Xenon}$, the initial Xenon distribution 
(ID-Xe) recorded during 10 seconds after peak activity and regional Xenon clearance for each of 4096 matrix points of the gamma camera were assessed. Thus, Xenon data were analysed both for flow distribution (ID-Xe) analogous to microsphere scintigraphy and as myocardial blood flow (MBF$\mathrm{Xe}, \mathrm{ml} / \mathrm{min}$ per $100 \mathrm{~g}$ ) derived from tracer washout. Assessment of myocardial blood flow was performed by analysis of the initial monoexponential washout slope by means of the Kety-Schmidt formula (Kety and Schmidt, 1945). Discrimination of extracardiac activity was achieved by fluoroscopically positioned external markers delineating the borders of the heart and by statistical means based on rejection of all matrix points that either reached their peak later than 15 seconds after Xenon injections or recorded less than 15 per cent of maximal isotope activity.



Fig. 1 Electrocardiograms and vectorcardiograms of the 4 patients. 
MICROSPHERE PERFUSION SCINTIGRAPHY Myocardial perfusion scintigraphy was performed with $99 \mathrm{~m}$ Tc-labelled human albumin microspheres (MPS-Tc). Regional activity was recorded both with the gamma camera and with a rectilinear scanner in conjunction with a core memory.

\section{Case reports}

The four women had been referred for diagnostic coronary arteriography and selection for surgery.

CASE 1 (c.s.)

A 33-year-old mother of two children. No family history of premature atherosclerosis. The risk factors included history of smoking 1 to 2 packets of cigarettes daily over 13 years. Oral contraceptives (Lyndiol $=2.5 \mathrm{mg}$ lynoestronol $+0.075 \mathrm{mg}$ mestranol) over the past 7 years. In March 1975 acute myocardial infarction without premonitory signs of angina pectoris. After the infarct there was no chest pain but complaints of dyspnoea and palpitation on exertion. Physical examination was normal. Blood pressure, serum cholesterol, triglycerides, and glucose were all within normal limits. Electrocardiogram and vectorcardiogram were consistent with old anterior myocardial infarction (Fig. 1A). Cardiac catheterisation with coronary and left ventricular angiocardiography eight months after the acute event showed left ventricular end-diastolic pressure at rest to be raised at $15 \mathrm{mmHg}$ (Table); akinesis of the apical two-thirds of the anterior wall with paradoxical motion of the apex, and normal coronary arteries (Fig. 2).

\section{CASE 2 (I.K.)}

A 40-year-old woman, previously in good health. The family history was negative for premature atherosclerosis. Risk factors included cigarette smoking (1 packet per day) over 16 years. Oral contraceptives had been taken for 18 months but were stopped one year before the infarction; from this time up to the infarction, monthly intramuscular injections of oestrogen (12 mg diethylstilboestrol) had been given; during the 12 days immediately preceding the infarction an additional oral oestrogen-progestogen combination (Primosiston = $2 \mathrm{mg}$ norethisteroneacetate $+0.01 \mathrm{mg}$ ethinyloestradiol) had been administered. In March 1974, a sudden crushing chest pain led to hospital admission for acute myocardial infarction. Ten hours after the first symptoms, streptokinase (1 750000 units) was infused over 16 hours. Eight months after the event she was referred for further evaluation because of intermittent burning retrosternal pain on strenuous exercise. Blood pressure, serum cholesterol, trigly- cerides, and glucose were all within normal limits at the time of the study. The electrocardiogram and vectorcardiogram showed anterolateral myocardial infarction (Fig. 1B). Cardiac catheterisation (Table) indicated normal resting haemodynamics; angiocardiography showed akinesis of the apical half of the anterior and apical third of the diaphragmatic wall of the left ventricle, and normal coronary arteries (Fig. 2).

Myocardial perfusion scintigraphy showed a large defect of activity corresponding to the akinetic left ventricular area (Fig. 3). The functional image of regional blood flow and the printout of flow rates showed the highest flow in the distribution of the left circumflex branch and in parts of the interventricular septum, whereas flow values were low in the inferior septum, the apex and the lower part of the anterior free wall of the left ventricle. Xenon washout was normal in a portion of the interventricular septum indicating that parts of this structure (probably supplied by the first septal branch) were perfused normally. Since perfusion scintigraphy (MPS-Tc) showed little activity in the septal area, the total mass of well-perfused interventricular myocardium may be presumed to be small. It seems probable that the obstruction in this case was located below the first septal branch; this would also be in agreement with the left ventriculogram showing an akinetic area below the papillary muscle, contractions in the middle and upper parts of the anterior wall still being normal (Fig. 2).

\section{CASE 3 (R.C.)}

A 34-year-old mother of one child. Family history negative for premature atherosclerosis. No history of smoking. Oral contraceptives (Eugynon $=0.5 \mathrm{mg}$ dl-norgestrel $+0.05 \mathrm{mg}$ ethinyloestradiol) had been taken for 13 years with only brief interruptions. She had a minor attack of chest pain five months before the event. In March 1975 she was admitted to hospital because of sudden severe retrosternal pain associated with nausea and vomiting; electrocardiogram and serum enzymes were diagnostic of acute inferolateral infarction. The course was uneventful. Blood pressure, serum cholesterol, triglycerides, and glucose were all within normal limits. Electrocardiogram and vectorcardiogram (Fig. 1C) indicated an inferior infarction, not recent. Cardiac catheterisation 5 weeks after the event showed normal haemodynamics (Table). Left ventriculogram showed hypokinesis of the diaphragmatic portion of the apex; the coronary arteries were normal (Fig. 2).

Microsphere scintigraphy and initial Xenon distribution revealed a perfusion deficit in the inferolateral region of the left ventricle. Xenon washout was found to be homogeneous (Table). 
Table

\begin{tabular}{|c|c|c|c|c|c|c|c|c|c|c|c|c|c|}
\hline \multirow{3}{*}{$\begin{array}{l}\text { Case } \\
\text { No. }\end{array}$} & \multirow{2}{*}{\multicolumn{2}{|c|}{ Angiocardiography }} & \multicolumn{6}{|c|}{ Systolic half axial shortening (\%) } & \multirow{2}{*}{\multicolumn{3}{|c|}{ Haemodynamics }} & \multirow{2}{*}{\multicolumn{2}{|c|}{$\begin{array}{l}\text { Myocardial perfusion: } \\
\text { regional reduction of }\end{array}$}} \\
\hline & & & \multicolumn{3}{|c|}{ Anterior } & \multicolumn{3}{|c|}{ Inferior } & & & & & \\
\hline & Coronary artery & Left ventricle & Basal & Medial & Apical & Basal & Media & al Apical & LVEDP & $\begin{array}{l}\text { Cardiac } \\
\text { index } \\
\text { ( } m \text { m Hg })\end{array}$ & $\begin{array}{l}\text { c Stroke } \\
\text { work } \\
\text { index } \\
\left(\mathrm{g} \mathrm{m} / \mathrm{m}^{2}\right. \\
B S A)\end{array}$ & $M B F-X E$ & $M P S-T C$ \\
\hline 1 & $\mathbf{N}$ & $\begin{array}{l}\text { Akinesis of } \\
\text { anterior wall }\end{array}$ & 13 & +4 & +12 & 58 & 70 & 43 & 15 & 3.5 & 57 & - & - \\
\hline 2 & $\mathbf{N}$ & $\begin{array}{l}\text { Akinesis of } \\
\text { anterior wall }\end{array}$ & 39 & 9 & 8 & 51 & 90 & +25 & 11 & 3.6 & 63 & $-65 \%$ & $-65 \%$ \\
\hline 3 & $\mathbf{N}$ & $\begin{array}{l}\text { Hypokinesis of } \\
\text { inferolateral } \\
\text { wall }\end{array}$ & 51 & 38 & 27 & 49 & 52 & 10 & 10 & $4 \cdot 2$ & 67 & $-7 \%$ & $-55 \%$ \\
\hline 4 & $\begin{array}{l}25 \% \text { left circum- } \\
\text { flex branch }\end{array}$ & $\begin{array}{l}\text { Akinesis of } \\
\text { inferolateral } \\
\text { wall }\end{array}$ & 37 & 23 & 55 & +4 & 0 & 9 & 10 & $4 \cdot 0$ & 59 & $-41 \%$ & $-45 \%$ \\
\hline
\end{tabular}

LVEDP, left ventricular end-diastolic pressure; regional reduction of MBF-Xe, per cent reduction of blood flow in damaged LV area as compared with normal LV area; in parenthesis blood flow in $\mathrm{ml} / \mathrm{min}$ per $100 \mathrm{~g}$ damaged LV area over flow in normal area. Reduction of MPS-Tc, regional scintigraphic astivity in damaged LV area in per cent of normal area. Abnormal systolic half axial shortening indicated by italic type.

CASE 4 (U.D.)

A 37 -year-old mother of two children. Family history negative for premature atherosclerosis. No smoking history. Oral contraceptives (Ovanon= $7 \times 0.08 \mathrm{mg}$ mestranol and $15 \times 0.075 \mathrm{mg}$ mestranol $\pm 2.5 \mathrm{mg}$ lynoestrenol) had been taken for 12 years. No symptoms were referrable to the cardiovascular system before an acute myocardial infarction in August 1974. At the time of cardiac catheterisation 16 months later, blood pressure, serum triglycerides, and glucose were normal, serum cholesterol was moderately raised at $7.7 \mathrm{mmol} / \mathrm{l}$ (normal: less than $6.5 \mathrm{mmol} / \mathrm{l}$ ). Electrocardiogram and vectorcardiogram showed old inferior myocardial infarction (Fig. 1D). Ventriculography indicated extensive akinetic area in the diaphragmatic wall of the left ventricle. Coronary arteriography was normal with the exception of an isolated focal mild stenotic lesion of less than 30 per cent luminal diameter in the mid portion of the dominant left circumflex coronary artery (Fig. 2). Perfusion scintigraphy and Xenon clearance demonstrated clearly diminished blood flow to the akinetic inferolateral portion of the left ventricle (Table).

\section{Discussion}

Several reports during the past few years have indicated that the use of oral contraceptives results in an 8- to 10-fold increase in the risk of venous thrombosis and pulmonary emboli as compared with subjects not taking oral contraceptives (Vessey and Doll, 1969). The risk of arterial thrombosis leading to ischaemic cerebrovascular events appears to be increased as well (Masi and Dugdale, 1970).
Furthermore, occurrence of myocardial infarction is reported with increasing frequency, and a statistically significant correlation between the mortality and morbidity of myocardial infarction in young women and the use of oral contraceptives has been shown by extensive epidemiological studies (Mann et al., 1975). Nevertheless the number of welldocumented cases is small, and precise information on the status of the coronary vessels and on concomitant atherogenic risk factors is available in only a few of these communications. To our knowledge this is the first study analysing regional myocardial perfusion in such patients.

\section{(a) MYOCARDIAL PERFUSION}

Regional myocardial perfusion was studied in 3 patients (Table). In spite of angiographically normal or almost normal coronary arteries, microsphere scintigrams (MPS-Tc) and initial Xenon distribution (ID-Xe) showed abnormal flow distribution in all 3 patients (Table). Reduced Xenon washout (MBF-Xe), however, was found only in the 2 patients with regional akinesis (cases 2 and 4) whereas regional Xenon clearance was normally homogeneous in the patient with inferolateral hypokinesis (case 3). This is thought to result mainly from the fact that analysis of the initial monoexponential slope of Xenon washout curves yields results that are weighted in favour of well-perfused areas within each solid angle and thus probably refers to remaining areas of viable myocardium rather than to scar tissue in hypokinetic areas. Moreover, adequate projection of the inferior left ventricular wall is difficult to achieve, since overlying normal anterior left ventricular wall areas tend to 
produce normal tracer washout curves.

In view of the unobstructed coronary arteries, one has to assume that the reduction of flow and perfusion observed in these patients is attributable either to reduced tissue oxygen demand or to structural changes at the precapillary or capillary level. Thus, reduced perfusion and flow rates in patients with myocardial infarction and severe coronary obstruction (Dwyer et al., 1973; Engel et al., 1976a) are concluded to be the result not only of the impediment of flow induced by obstructions of the large extramural coronary arteries; they probably also reflect alterations at the cellular level which increase resistance to flow after myocardial infarction.

(b) MECHANISM OF MYOCARDIAL

INFARCTION DURING ORAL

CONTRACEPTIVE MEDICATION

The localised perfusion deficit in spite of normal

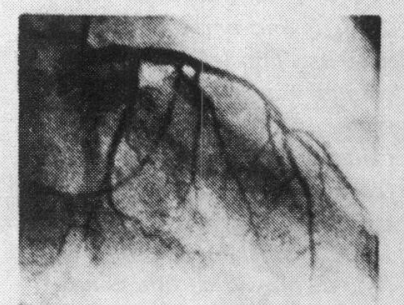

a.
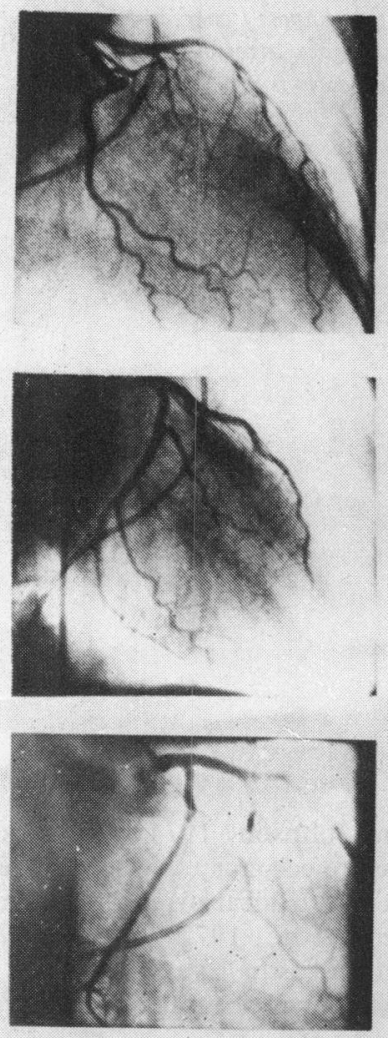

LCA RAO
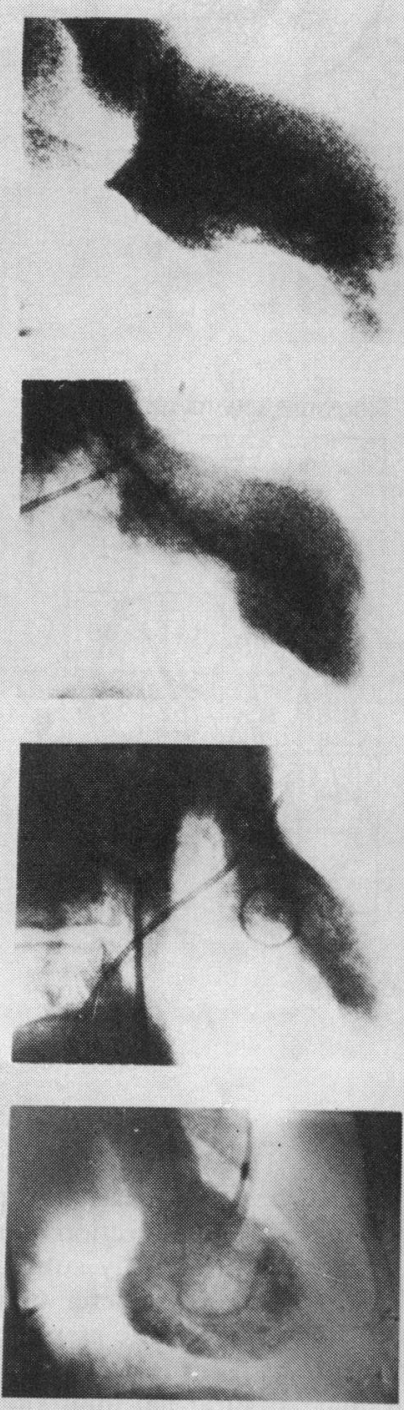

LV syst. RAO

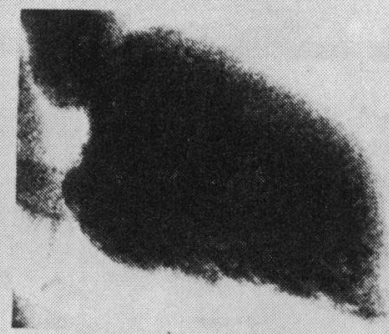

$156 / 75$

C.S. 1941

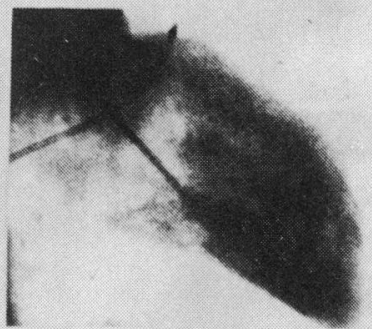

$370 / 75$

I.K. 1934
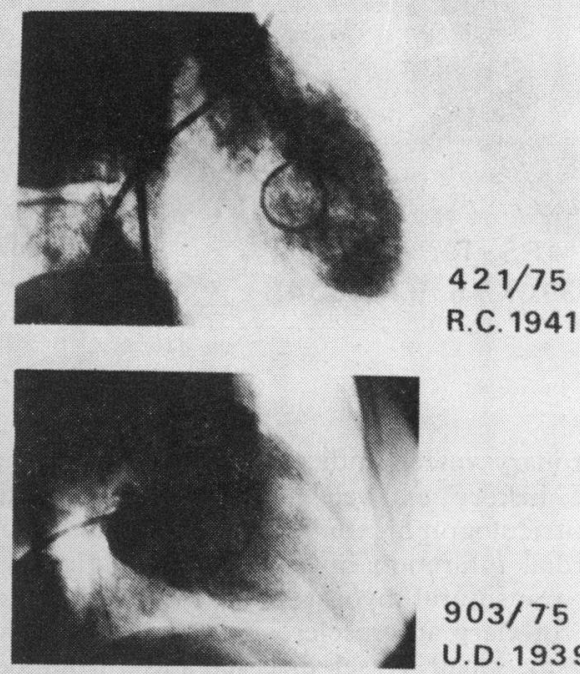

$903 / 75$

U.D. 1939

LV diast. RAO

Fig. 2 Arteriograms of the left coronary artery (LCA) and left ventriculograms in right anterior oblique (RAO) projections. 


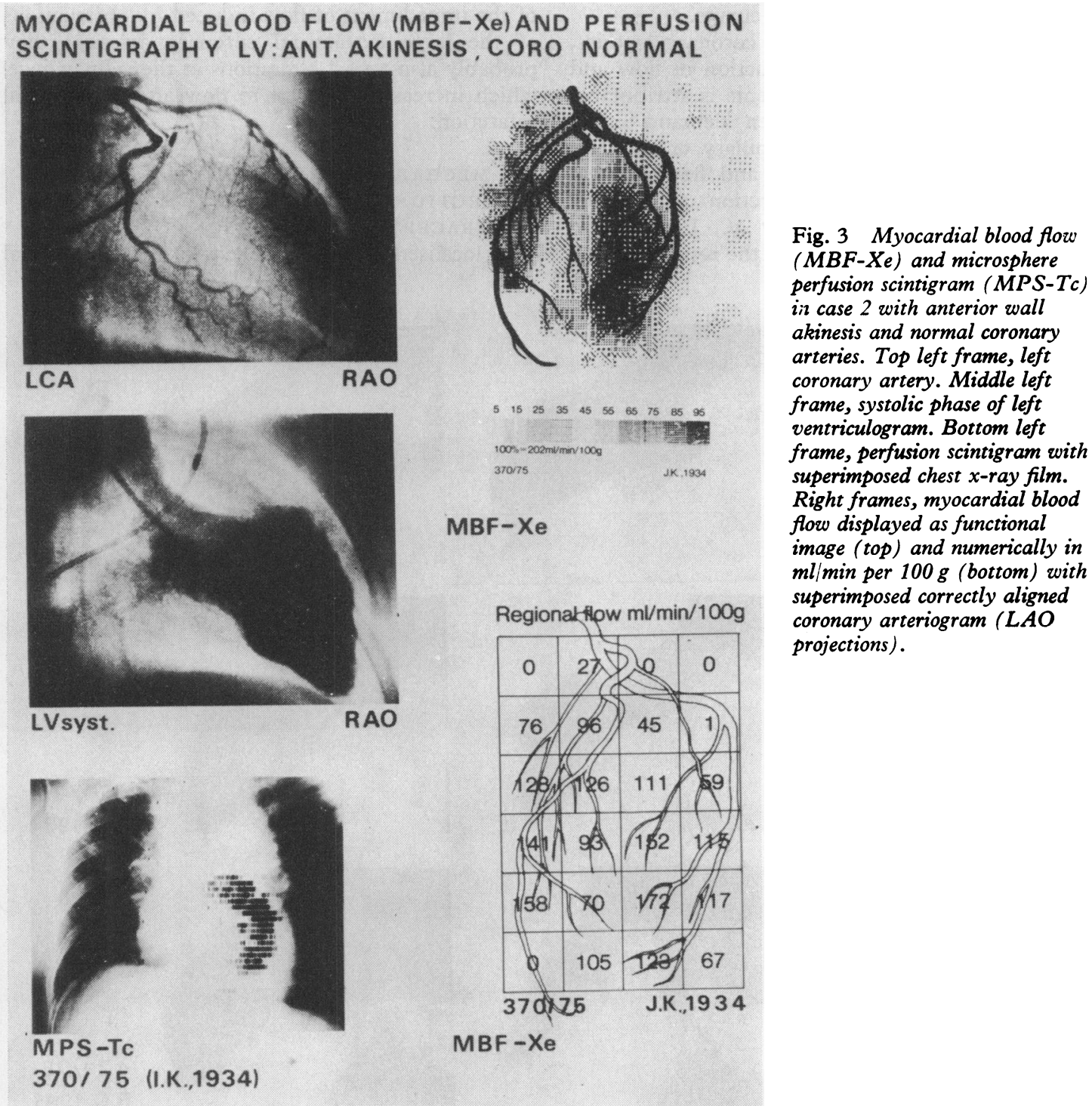

coronary vessels indicates myocardial damage, and the history as well as electrocardiographic and ventriculographic findings are diagnostic of myocardial infarction in each of our patients. Causes for transmural myocardial infarction in the absence of coronary atherosclerosis include coronary artery spasm, small vessel disease, and thromboembolic phenomena with spontaneous restitution of vessel patency.

The role of coronary artery spasm in the production of myocardial infarction has been discussed re- peatedly (Carleton and Johnson, 1974), but myocardial infarction related to coronary spasm has been reported only subsequent to local arterial stimulation by catheter (Cheng et al., 1972; Engel et al., 1976b). The assumption of 'small vessel disease' is difficult to accept as the primary cause of transmural myocardial infarction.

In our opinion the most plausible hypothesis explaining myocardial infarction in young women taking oral contraceptives is thromboembolic mechanism. The way in which oral contraceptives 
might produce thrombotic coronary occlusions is hypothetical, but is analogous to their thrombogenic effect in peripheral and hepatic veins and in cerebral arteries. Oestrogens are known to enhance coagulability by increasing platelet adhesiveness and by augmenting the activity of clotting factors VII and $\mathrm{X}$ (Dugdale and Masi, 1969). In addition, microscopical changes of the arterial wall that might be related to thrombus formation have occurred after oestrogen medication (Irey et al., 1970).

A review of communications on possible oestrogen-related myocardial infarction based on angiographic results (Dear and Jones, 1971; Glancy et al., 1971; Waxler et al., 1971; Kimbiris et al., 1972; Henderson et al., 1973; Maleki and Lange, 1973; Ciraulo, 1975) or necropsies (Hartveit, 1965; Naysmith, 1965; Osborn, 1965; Dalgard and Gregersen, 1969; Stout, 1969; Weiss, 1972) tends to corroborate this assumption because these reports document a higher than average incidence of coronary thrombosis and little evidence of generalised atherosclerosis. In contrast, diffuse and widespread atherosclerotic coronary disease is the common finding after myocardial infarction of atherosclerotic aetiology (Roberts and Buja, 1972). The observations presented here are not sufficient to decide whether myocardial infarction that might be related to contraceptive medication is a discrete disease entity unrelated to coronary atherosclerosis or common atherogenic risk factors. This hypothesis does not agree with observations by Oliver (1970) and Radford and Oliver (1973) who report that the risk of taking oral contraceptives is increased most in women with atherogenic risk factors.

The finding of normal or almost normal coronary arteries in our patients is not inconsistent with thromboembolic occlusions. Spontaneous resolution of occlusive coronary clots has been shown experimentally by Weisse et al. (1969). In man complete resolution of thrombotic material accidentally embolised into the coronary arteries during cardiac catheterisation has been documented repeatedly (Agarwal et al., 1975). Absence of atherosclerotic lesions that are known to inhibit thrombolysis is felt to enhance restoration of vessel patency under these circumstances (Weisse et al., 1969).

In conclusion a rare aetiological relation between the use of oral contraceptives and myocardial infarction appears possible in susceptible women. The relation between myocardial infarction related to contraceptive pills and coronary atherosclerosis remains undefined. As the regional myocardial flow studies indicate, perfusion of previously infarcted left ventricular wall areas is reduced even after complete restoration of vessel patency.

\section{References}

Agarwal, B., Ashraf, M. M., Coles, D. M., and Bloomfield, D. A. (1975). Resolution of an iatrogenic coronary artery thromboembolus. Chest, 67, 357-359.

Ashburn, W. L., Braunwald, E., Simon, A. L., Peterson, K. L., and Gault, J. H. (1971). Myocardial perfusion imaging with radioactive-labeled particles injected directly into the coronary circulation of patients with coronary artery disease. Circulation, 44, 851-865.

Carleton, R. A., and Johnson, A. D. (1974). Coronary arterial spasm-a clinical entity? Modern Concepts of Cardiovascular Disease, 18, 87-91.

Cheng, T. O., Bashour, T., Singh, B. K., and Kelser, G. A. (1972). Myocardial infarction in the absence of coronary arteriosclerosis-result of coronary spasm (?). American fournal of Cardiology, 30, 680-689.

Ciraulo, D. A. (1975). Recurrent myocardial infarction and angina in a woman with normal coronary angiograms. American fournal of Cardiology, 35, 923-926.

Dalgard, J. B., and Gregersen, M. (1969). Coronarthrombose nach hormonaler Antikonzeption. Beiträge zur gerichtlichen Medizin, 25, 224-234.

Dear, H. D., and Jones, W. B. (1961). Myocardial infarction associated with the use of oral contraceptives. Annals of Internal Medicine, 74, 236-239.

Dugdale, M., and Masi, A. T. (1969). Effects of oral contraceptives on blood clotting. In Second Report on Oral Contraceptives, p. 43. Advisory Committee on Obstetrics and Gynecology, Washington, D.C., Food and Drug Administration.

Dwyer, E. M., Dell, R. B., and Cannon, P. J. (1973). Regional myocardial blood flow in patients with residual anterior and inferior transmural infarction. Circulation, 48, 924-935.

Engel, H.-J., Heim, R., Liese, W., Hundeshagen, H., and Lichtlen, P. (1976a). Regional myocardial perfusion at rest in coronary disease assessed by microsphere scintigraphy and inert gas clearance. American fournal of Cardiology, 37, 134.

Engel, H.-J., Page, H. L., and Campbell, W. B. (1976b). Coronary artery spasm as the cause of myocardial infarction during coronary arteriography. American Heart fournal, 91, 501-506.

Glancy, D. L., Marcus, M. L., and Epstein, S. E. (1971). Myocardial infarction in young women with normal coronary arteriograms. Circulation, 44, 495-502.

Hartveit, F. (1965). Complications of oral contraception. British Medical fournal, 1, 60-61.

Henderson, R. R., Hansing, C. E., Razavi, M., and Rowe, G. G. (1973). Resolution of an obstructive coronary lesion as demonstrated by selective angiography in a patient with transmural myocardial infarction. American fournal of Cardiology, 31, 785-788.

Hundeshagen, H., Geisler, S., Dittmann, P., Lichtlen, P., and Engel, H.-J. (1976). Quantitative scintigraphic display of the myocardial blood flow-technique and clinical evaluation. European Fournal of Nuclear Medicine, 1, 107-115.

Irey, N. S., Manion, W. C., and Taylor, H. B. (1970). Vascular lesions in women taking oral contraceptives. Archives of Pathology, 89, 1-8.

Kety, S. S., and Schmidt, C. F. (1945). The determination of cerebral blood flow in man by use of nitrous oxide in low concentrations. American fournal of Physiology, 143, 53-66.

Kimbiris, D., Segal, B. L., Munir, M., Katz, M., and Likoff, W. (1972). Myocardial infarction in patients with normal patent coronary arteries as visualized by cinearteriography. American fournal of Cardiology, 29, 724-728. 
Lichtlen, P., Engel, H.-J., and Hundeshagen, H. (1976). Regional myocardial blood flow in patients without coronary artery disease, yet proven myocardial infarctions. American Fournal of Cardiology, 37, 151.

Maleki, M., and Lange, R. L. (1973). Coronary thrombosis in young women on oral contraceptives: report of two cases and review of the literature. American Heart fournal, 85, 749-754.

Mann, J. I., Vessey, M. P., Thorogood, M., and Doll, R. (1975). Myocardial infarction in young women with special reference to oral contraceptive practice. British Medical fournal, 2, 241-245.

Masi, A. T., and Dugdale, M. (1970). Cerebrovascular diseases associated with the use of oral contraceptives. Annals of Internal Medicine, 72, 111-121.

Naysmith, J. H. (1965). Oral contraceptives and coronary thrombosis. British Medical fournal, 1, 250.

Oliver, M. F. (1970). Oral contraceptives and myocardial infarction. British Medical fournal, 2, 210-213.

Osborn, G. R. (1965). Oral contraception and thrombosis. British Medical fournal, 1, 1128.

Radford, D. J., and Oliver, M. F. (1973). Oral contraceptives and myocardial infarction. British Medical fournal, 3, $428-430$.

Roberts, W. C., and Buja, L. M. (1972). The frequency and significance of coronary arterial thrombi and other observations in fatal acute myocardial infarction. American fournal of Medicine, 52, 425-444.
Ross, R. S., Ueda, K., Lichtlen, P., and Rees, J. R. (1964). Measurement of myocardial blood flow in animals and man by selective injection of radioactive inert gas into the coronary arteries. Circulation Research, 15, 28-41.

Stout, C. (1969). Coronary thrombosis without coronary atherosclerosis. American fournal of Cardiology, 24, 564-569.

Vessey, M. P., and Doll, R. (1969). Investigation of relation between use of oral contraceptives and thromboembolic disease-a further report. British Medical fournal, 2, 651-657.

Waxler, E. B., Kimbiris, D., van den Broek, H., Segal, B. L., and Likoff, W. (1971). Myocardial infarction and oral contraceptive agents. American fournal of Cardiology, 28, 96-101.

Weiss, S. (1972). Myocardial infarction and oral contraceptives. New England fournal of Medicine, 286, 436-437.

Weisse, A. B., Lehan, P. H., Ettinger, P. O., Moschos, C. B., and Regan, T. J. (1969). The fate of experimentally induced coronary artery thrombosis. American fournal of Cardio$\log y, 23,229-237$.

Requests for reprints to Dr. H.-J. Engel, Abt. Kardiologie, Medizinische Hochschule Hannover, Karl-Wiechert-Allee 9, 3000 Hannover, WestGermany. 